

\section{Cafeteras mutantes. Tecnología y cambio en los objetos de diseño}

Ashby Solano'

Resumen Este trabajo aborda la relación entre la transformación de un objeto de diseño (específicamente, las cafeteras) y el desarrollo tecnológico. Una revisión detallada de cinco tipos de cafeteras, analizadas con base en las categorías de uso, función, materiales, procesos e interfaz, permite describir cómo la revolución tecnocientífica ha modificado estos atributos torales.

Palabras clave diseño industrial, objeto de diseño, tecnología, transformación, cafeteras.

Abstract This work addresses the relationship between the transformation of a design object (specifically, the coffee pot) and technological development. A detailed review of five types of coffee pots, including the categories of use, function, materials, processes and interfaces, allows to explain how the scientific and technological revolution has modified these main attributes.

Keywords industrial design, design object, technology, change, coffee pot 


\section{Existen diferentes aspectos de la sociedad industrial que se ven afectados a razón de los cambios tecnológicos, entre ellos podemos mencionar la economía, los medios y métodos de producción, entre otros.}

La tecnología ha generado nuevos modos de producir, comunicar, gestionar y vivir (Castells, M. 1996), desde inicios de los años 70, sobre todo en países desarrollados como Estados Unidos, en donde encontramos un claro ejemplo de cómo la tecnología de la información ha construido nuevos paradigmas tecnológicos. Como consecuencia de esto las empresas han tenido que cambiar sus modelos organizacionales para poder adaptarse de forma inmediata a los rápidos cambios en torno a este asunto.

Como lo menciona Castells la sociedad no dicta el curso del cambio tecnológico, éste depende de una relación compleja entre muchos factores, como las invenciones personales, los descubrimientos científicos, las invenciones tecnológicas, y las aplicaciones sociales. Citando a este mismo autor: "La tecnología no determina la sociedad: la plasma. Pero tampoco la sociedad determina la innovación tecnológica: la utiliza." (Castells, M. 1996).
Esta mezcla de factores ha dado pie a lo que actualmente conocemos como "Tecnociencia", praxis de la ciencia y tecnología que inicia su auge en los años 80 en Estados Unidos y a la que algunos autores han descrito como la fuerza productiva fundamental y característica de la sociedad informacional.

El término de Sociedad Informacional o Sociedad de la Información (actualmente también se puede Ilamar Sociedad del Conocimiento), es utilizado por muchos autores y de distintas maneras, sin embargo para fines de este documento utilizaremos el concepto que la define como la organización social en donde las tecnologías que facilitan la transmisión, procesamiento y generación de información juegan un papel primordial en diferentes campos de ámbito social, cultural y económico.

Existen cinco elementos que ayudan a definir a esta sociedad, el elemento tecnológico, el eco- 
nómico, el ocupacional, el tiempo y espacio y el cultural (Estudillo García J. 2001), sin embargo, no es nuestro objeto de estudio adentrar más este concepto.

La tecnociencia ha modificado la forma en la que el mundo concibe la innovación y la generación de nuevos productos, ya que no se trata sólo de investigar y generar nuevos conocimientos científicos alrededor de un tema, sino también de generar desarrollos tecnológicos que resulten en productos nuevos, originales o invenciones. El autor Javier Echeverría define a la tecnociencia como una convergencia entre nanotecnología, biotecnologías, tecnologías de la información y ciencias cognitivas, y apunta ciertos rasgos que la caracterizan como: la investigación y conocimiento se gestiona de manera industrial o empresarial, orientado a la eficiencia y rentabilidad; el resultado es fruto del trabajo entre grandes equipos híbridos, plurales y complejos; sirve para el desarrollo económico y empresarial; la informática y las tecnologías de la información y comunicación son sus principales herramientas; y se busca crear nuevos productos que capten mercados y generen beneficios, reforzando la triada empresa-capital-mercancía. (Echeverría J. 2003).

Dentro de las especialidades que generan nuevos productos encontramos al Diseño Industrial, mismo que también se ha visto afectado por esta revolución tecnocientífica, por el crecimiento exponencial de la computación y microelectrónica, por los procesos de globalización económica e industrial y por el desarrollo tecnológico de los sistemas productivos. Este se ha convertido en un interventor del cambio tecnológico, y de la relación entre la sociedad, la tecnología y el medio ambiente, debido a su estrecha relación con todos estos rubros en el desarrollo de sus objetos.
Podemos mencionar diferentes autores importantes en el campo que han definido el significado de diseño industrial, como es el caso de Tomás Maldonado (diseñador industrial reconocido por ser uno de los personajes más influentes en el campo teórico y práctico del diseño) u organizaciones como el ICSID (International Council of Societies of Industrial Design), sin embargo para este estudio utilizaremos la presentada por el diseñador industrial español José Manuel Mateo, el cual lo define como:

El diseño industrial es una actividad intelectual, técnica, creativa y proyectual que establece, siempre con anterioridad y mediante una metodología que permite soluciones objetivas, todas las propiedades necesarias para la más adecuada fabricación seriada de cualquier tipo de objeto y/o artefacto.

El diseño industrial no solo se encarga de los aspectos técnicos-tecnológicos que han de permitir siempre la más optimizada fabricación de los objetos sino que debe también mostrar, a través de ellos, el nivel de progreso vivido mediante la innovación constante e incorporar todas las propiedades necesarias para que éstos puedan resultar productos. Es decir, debe ocuparse también de las necesidades del mercado y de todos los condicionantes y aspectos funcionales y comunicativos-culturales de los objetos.

El diseño industrial siempre se establece como mediador entre las necesidades de los usuarios y las necesidades de las industrias y/o empresas, buscando un obligado equilibrio del beneficio y las soluciones entre todas las partes. Entre estos equilibrios debe primar el respeto humano y medioambiental. (Mateo Hernández J., 2013).

El diseño industrial se ha tenido que adaptar a dos grandes cambios tecnológicos a lo largo de la 
historia, el primero situado cronológicamente en la última fase de la II Guerra Mundial, en donde desplazó a las artes y oficios y se fusionó con la técnica para entrar dentro del sistema productivo mecanicista (Durán O., 2011); y la segunda que está directamente relacionada con la revolución tecnocientífica, en donde el diseño ha tenido que adaptarse y generar productos resultado de la mezcla de ciencia, tecnología e innovación.

El término de "producto", resultado del diseño industrial, ha tenido que trascender lo físico y sus características en general han tenido que aliarse con la tecnología. La forma ya no está necesariamente relacionada con la función y las nuevas tecnologías han dado espacio a nuevas necesidades o demandas como la de personalización de los productos y que estos puedan ser modificados constantemente usando herramientas como softwares o internet. Sumado al desarrollo de interfaces y relación con softwares y tecnologías de la información y la comunicación, la innovación tecnológica también ha tenido un fuerte impacto en la creación de nuevos materiales para el diseño y la evolución de los sistemas productivos y líneas de producción.

Dicha revolución da lugar a una nueva naturaleza de artefactos que deben fusionar nuevas formas de trabajo, conocimientos, relaciones de medios y producción. En donde dichos artefactos dominan la elite de los productos con la mejor tecnología involucrada en los objetos de diseño para consumo. (Durán O., 2011).

Partiendo de esta base, el objetivo de este trabajo consiste en describir cómo es que las cafeteras han cambiado con base en la evolución tecnológica que en las últimas décadas ha influenciado el desarrollo del diseño industrial, estableciendo una relación entre la tecnología los objetos, el café y el cambio; entendiendo por tecnología a

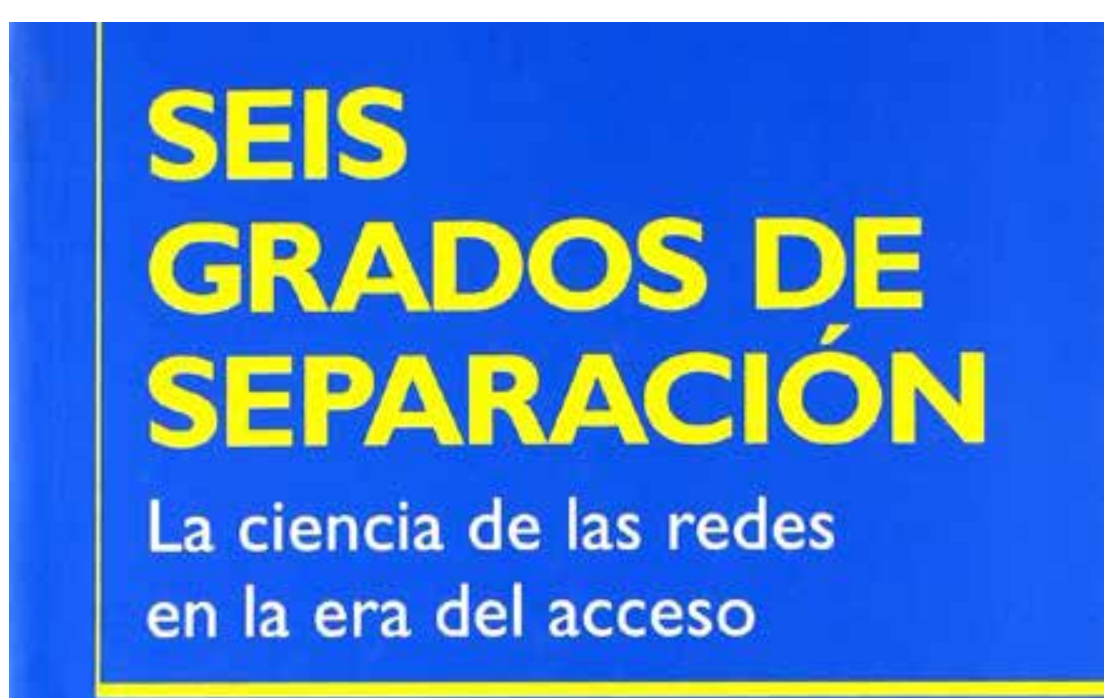

\section{DUNCAN J. WATTS}

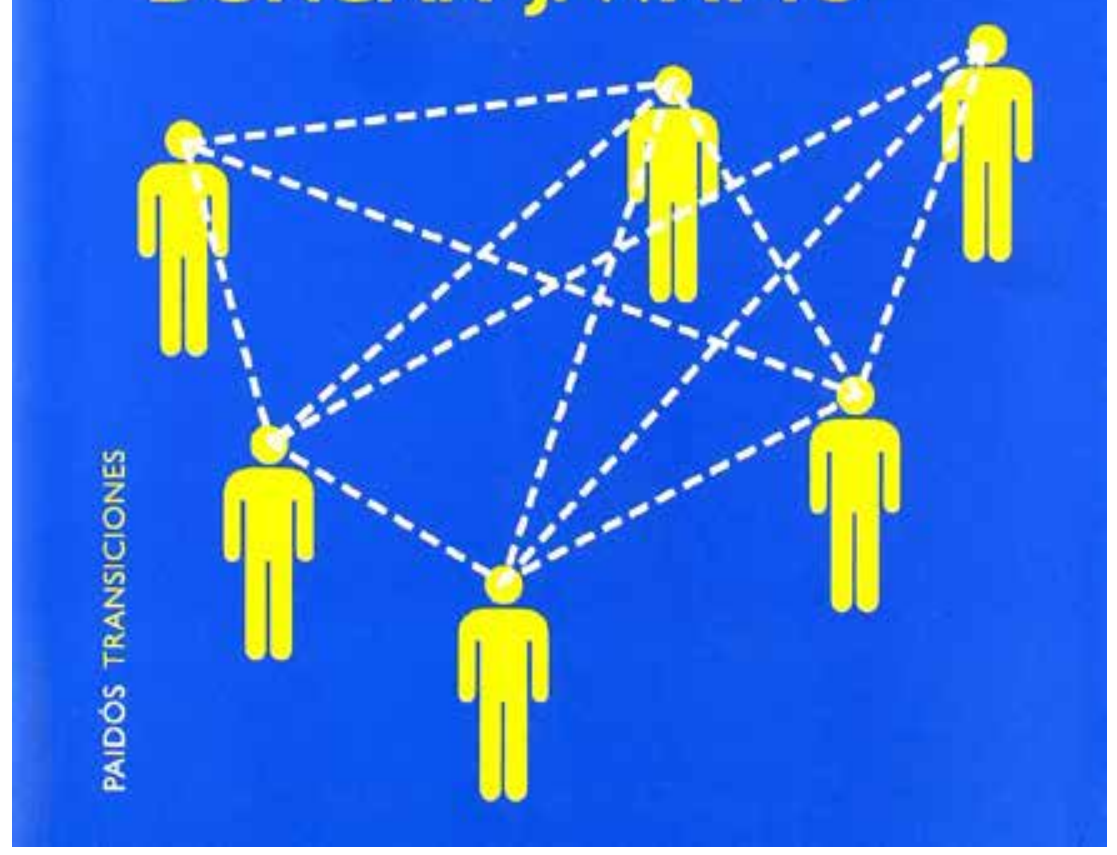

http://www.amazon.es/

un conjunto de elementos complejos, resultados de la ciencia, la ingeniería y el diseño y no solo como un objeto digitalizado. También considero importante resaltar que en lo que hace a la tecnología, tomo distancia de los enfoques morales que dan por hecho la bondad o maldad del factor tecnológico.

\section{Metodología}

El primer paso para determinar el objeto de estudio consistió en realizar un análisis de imágenes en torno a productos de diseño industrial relacionados con el café, partiendo de la taza, usando el sistema de "Seis grados de separación" teoría propuesta en 1930 por Frigyes Karinthy. Esta teo- 
ría plantea que todos estamos conectados con un máximo de separación de seis eslabones, concepto en el cual profundiza aún más el autor Duncan Watts en su libro Seis Grados de Separación (Watts Duncan, 2006). Para esta investigación los grados que surgieron fueron: en primer grado, tazas contenedoras de café, esto llevó a un segundo grado, vasos contenedores de café; a su vez éstos nos llevan al tercer grado, cupholders para vasos de café. De este último grado surgieron muchas imágenes relacionadas con gadgets tecnológicos que se incorporan al diseño de este último objeto, por ejemplo: un cupholder que integra una extensión para colocar los teléfonos celulares y que los usuarios puedan ir navegado, escribiendo o utilizando su móvil con ambas manos mientras su café se sostiene en la otra parte de la extensión. Esto nos conectó con el cuarto y último grado de separación en los objetos tecnológicos asociados con el café, tales como accesorios de escritorio para calentar una taza, cargadores de celular conectados a diferentes contenedores, tazas termocromáticas que te indican la temperatura, aplicaciones para celular o tablets que indican el tipo de bebida favorita del usuario.

Con base en esta asociación de objetos se decidió trabajar con las cafeteras debido a que son productos más complejos, con más componentes o aspectos a evaluar que una taza u otros accesorios para nichos de mercado más pequeños. La cafetera es suficientemente compleja y universal, por lo que se antoja como un interesante objeto de análisis.

Se estableció como objetivo el describir el cambio de los productos relacionados con el café a lo largo de los últimos años, para explorar la relación entre la transformación del objeto elegido y el desarrollo tecnológico. Para ello se retoma la línea de trabajo propuesta en el estudio de caso The design evolution of medical devices: moving from object to user. (Xue, L., Yen, C.C., Boucharenc, C. and Choolani, M., 2008) con algunas modificaciones. En este trabajo, el enfoque se relaciona con la evolución de los dispositivos médicos en varias características del diseño, como la función, la ergonomía, la tecnología, la estética, el diseño universal o inclusivo y el diseño emocional; para el caso actual el enfoque será hacia la función, el uso, los materiales, los procesos industriales y la interfaz.

\section{Características de producto}

Fueron planteados siete aspectos para el desarrollo de este estudio de caso para observar la influencia del desarrollo tecnológico, destacando entre ellos: los materiales, los procesos y la interfaz. Estos aspectos son el resultado de la experiencia desarrollada en el ámbito del diseño industrial y se considera que el análisis de los mismos permite entender de manera muy redonda los productos desarrollados en este ámbito. El año de invención y el diseñador son referencias importantes para poder establecer una línea de tiempo en torno a la cual determinar los cambios relevantes en el objeto estudiado. La función es la característica mediante la cual los mismos demuestran su finalidad y generan una interacción directa con el usuario. Es la que le da al producto el genuino sentido de ser práctico e utilitario. Para fines de este trabajo se utiliza este atributo con el propósito de describir si la tecnología ha influenciado las funciones principales o secundarias de las cafeteras. También se describirán los tipos de café producto del objeto de estudio.

El uso se refiere a la utilización del objeto para cumplir con su función principal en aras de o resultado específico. Se analizarán los pasos a seguir para obtener el producto final en las cafeteras y cómo el desarrollo tecnológico ha intervenido en la sencillez o complejidad de los mismos, con el fin de mejorar la relación usuario-producto. 


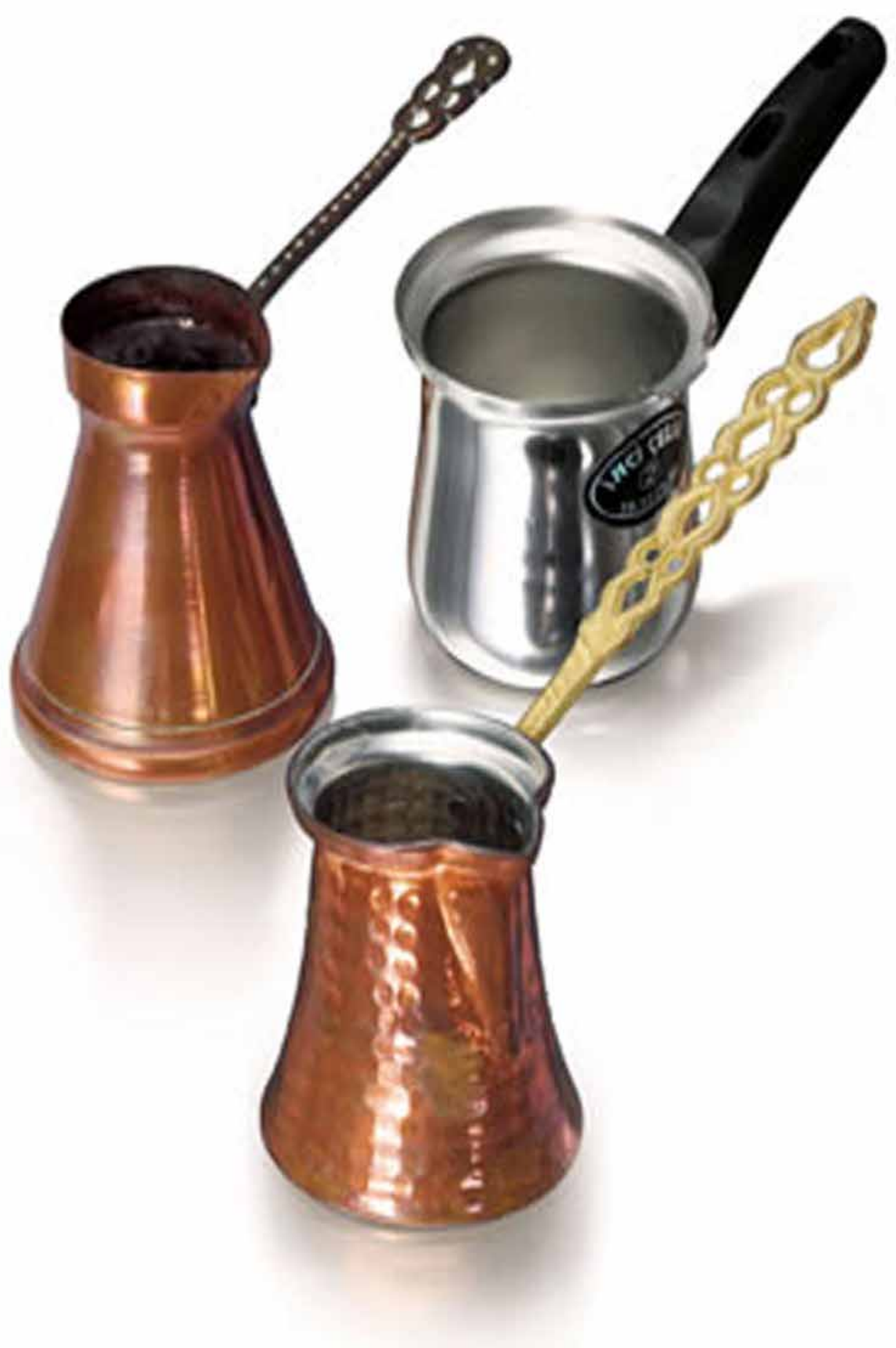

www.cafedecolombia.com
El humano es capaz de diseñar y crear objetos $u$ artefactos de los materiales, mismos que pueden transformarse y agruparse para dar nuevos valores técnicos y decorativos a la materia. Estos son de los elementos más influenciados por la revolución tecnológica, y sus límites se han expandido, al punto que nos han permitido generar nuevas combinaciones, procesos, mezclas y estilos.

Los procesos industriales y los medios de producción están estrechamente vinculados a los materiales, las posibilidades técnicas se han expandido y permiten así al diseñador tener una amplia gama de posibilidades para manufacturar el producto, aumentando la producción y la economía a escala, disminuyendo los desperdicios e inventarios, y mejorando la relación costo-calidad-beneficio.

La interfaz es el medio por el cual el objeto y el usuario pueden establecer una comunicación unidireccional o bidireccional, misma que puede alcanzarse por medio de textos, diagramas, interfaces gráficas, sonidos o indicadores luminosos. A raíz de la revolución digital hemos sido testigos de cambio de cómo los objetos se comunican con los usuarios, pasando de indicadores análogos a una indiscutible tendencia hacia el diseño de interacción o diseño de comunicación enfocado en lo digital, en las interfaces gráficas (GUI), interacción persona-computador $(\mathrm{HCl})$ e interfaz de usuario (HMI).

Las cafeteras estudiadas fueron las siguientes: cafetera turca; cafetera de émbolo, pistón o francesa; cafetera expreso; cafetera de goteo manual o Chemex; y cafetera de goteo automático. El proceso de selección consideró cuatro aspectos: la diferencia entre el tipo de café que se hace en cada una, el tipo de proceso que se realiza para obtener el producto final, la popularidad en el mercado y su uso fuera en el hogar. En relación a la selección de la marca o en algunos casos de 
modelos específicos dentro de cada tipo de cafetera, la elección se hizo con base en la primera marca que lanzó al mercado ese tipo de cafetera, ejemplo, en el caso de la cafetera expreso la marca tomada como punto de partida es Gaggia, por ser la primera en comercializar una cafetera para expreso casera.

La cafetera más antigua es la de café turco, la cual data del siglo XVI y no existen registros en relación a su inventor o diseñador. Dicho modelo ha sido fuente de muchas modificaciones, sin embargo la que se considera más significativa para los fines de este trabajo es la hecha por la marca Beko en 2012, la cual convirtió a la cafetera turca tradicional a una cafetera eléctrica automática con el modelo BK-2113M. En 1852 los franceses Mayer y Delforge inventaron la mejor conocida como cafetera francesa, misma que no ha sufrido mayor modificación, más que las patentadas, por los italianos Attilio Calimani en 1929 y Faliero Bondanini en 1958.En 1901 nace la cafetera expreso del ingeniero Luigi Bezzera quien le vendió los derechos de distribución a Desiderio Pavoni en 1905 para ser comercializada exitosamente; sin embargo no es hasta 1945 que este modelo se lleva a los hogares por el fundador de las cafeteras Gaggia, Achille Gaggia. Dicha cafetera registra múltiples cambios a lo largo de la historia, su funcionamiento ha sido adaptado a múltiples formas y modelos a razón de la revolución tecnológica, destacando entre ellas: la cafetera italiana, que también es una cafetera expreso, patentada por Luigi De Ponti en nombre de Alfonso Bialetti en 1933; la cafetera expreso de cápsulas, la cual muestra un cambio en la forma de presentar el café no de forma tradicional sino en cápsulas plásticas cerradas herméticamente e inventadas por Eric Favre en 1994; la cafetera GranBaristo Avanti de Phillips presentada en el IFA Feria líder en el mundo de la electrónica de consumo y electrodomésticos en 2013, la cual presenta un sistema de control de actividades por medio de una aplicación para móviles o tabletas; y por último la Handspresso una cafetera portátil comercializada en dos versiones, una manual y otra eléctrica, que funciona con la energía del encendedor del auto. Estos últimos modelos no serán estudiados con tanto detalle, aunque sí son una referencia cronológica importante.

Después de la cafetera antes referida, Peter Schlumbohm diseñó la cafetera de goteo manual, mejor conocida como Chemex, basada en el diseño de los equipos de laboratorio de Erlenmeyer. Cabe destacar que esta cafetera es un ícono del diseño y se encuentra en la colección del MoMA Museum of Modern Art de Nueva York.

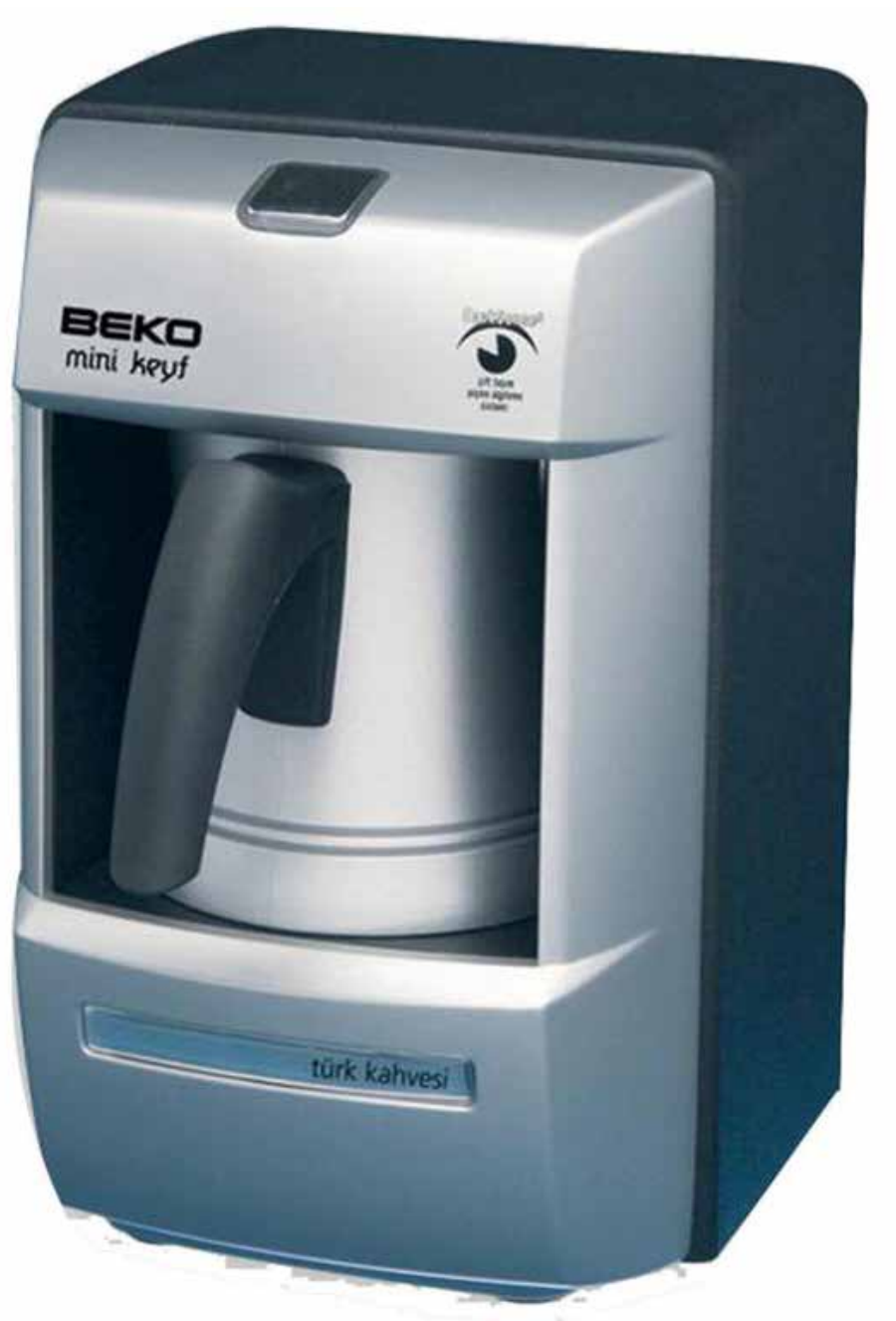

brand-store.com 


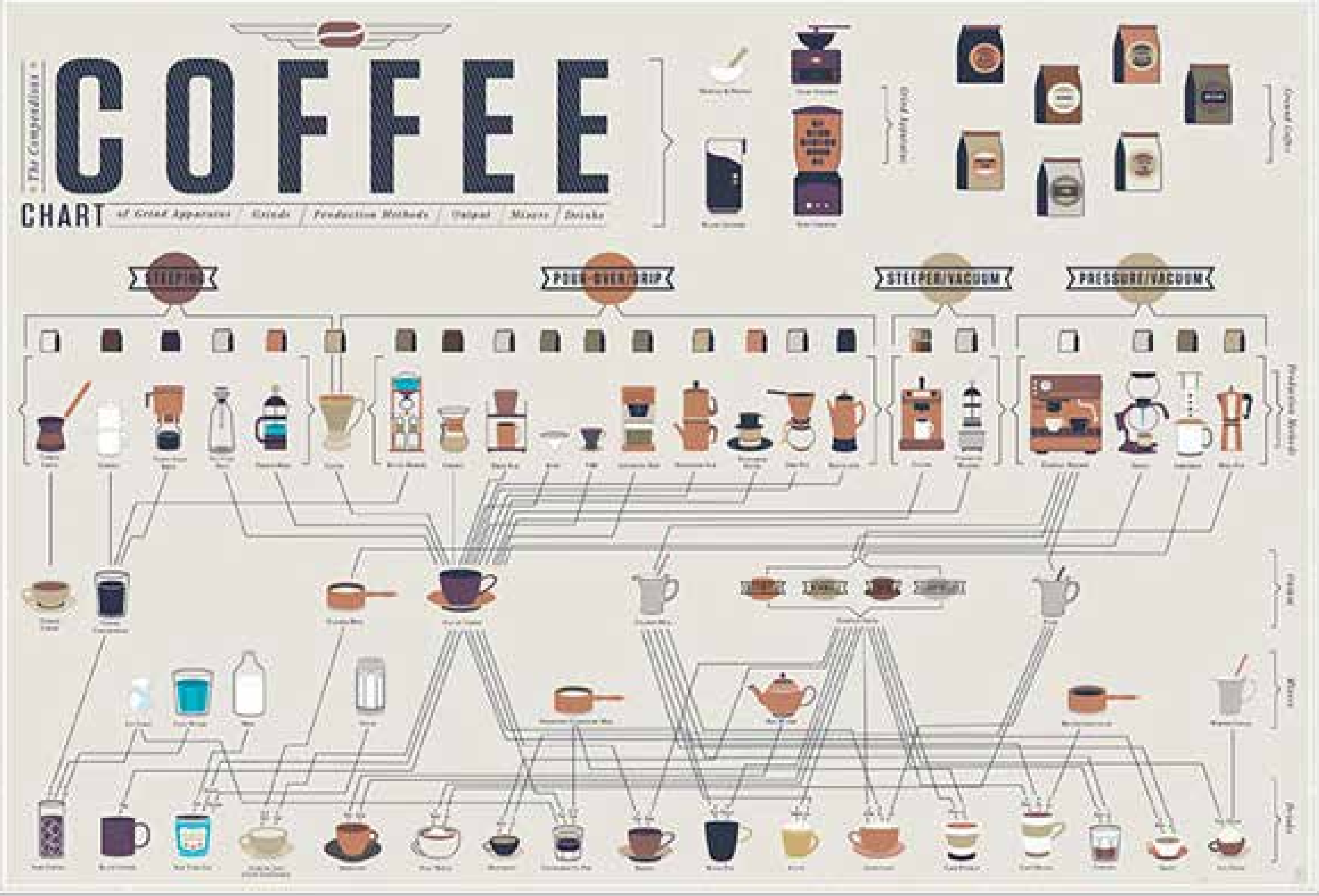

http://www.aromadecafe.es/

Por último se consideró la cafetera de goteo automático, basada en el modelo Wigomat, patentada en 1954, considerada como la primera cafetera eléctrica de goteo automático; en 1972 Vince Marotta contribuyó a la popularización de este modelo tanto en casa como oficinas, debido a su facilidad de uso, limpieza, desempeño, seguridad para el usuario y a su capacidad de máxima de preparación.

\subsection{Función}

La influencia de la revolución tecnocientífica en términos de función y producto resultante de las cafeteras es muy evidente, en la cafetera turca su función se limita a la elaboración del café de esa variedad, que es agrio o amargo, sin filtrar y se prepara de forma manual, usando el calentamiento directo de la cocina y siendo este el único café que se prepara hervido y que según muchos expertos pierde muchos aromas por este motivo. Luego notamos que la mayor parte de las cafeteras operan con base en el filtrado, esto debido integración de nuevos procesos y materiales en la manufactura. En la cafetera francesa se prepara café filtrado con un filtro que puede ser de nylon, goma o aluminio y la intensidad del mismo puede variar de acuerdo con el tiempo 


\section{BREWING CONTROL CHART}

1. 6

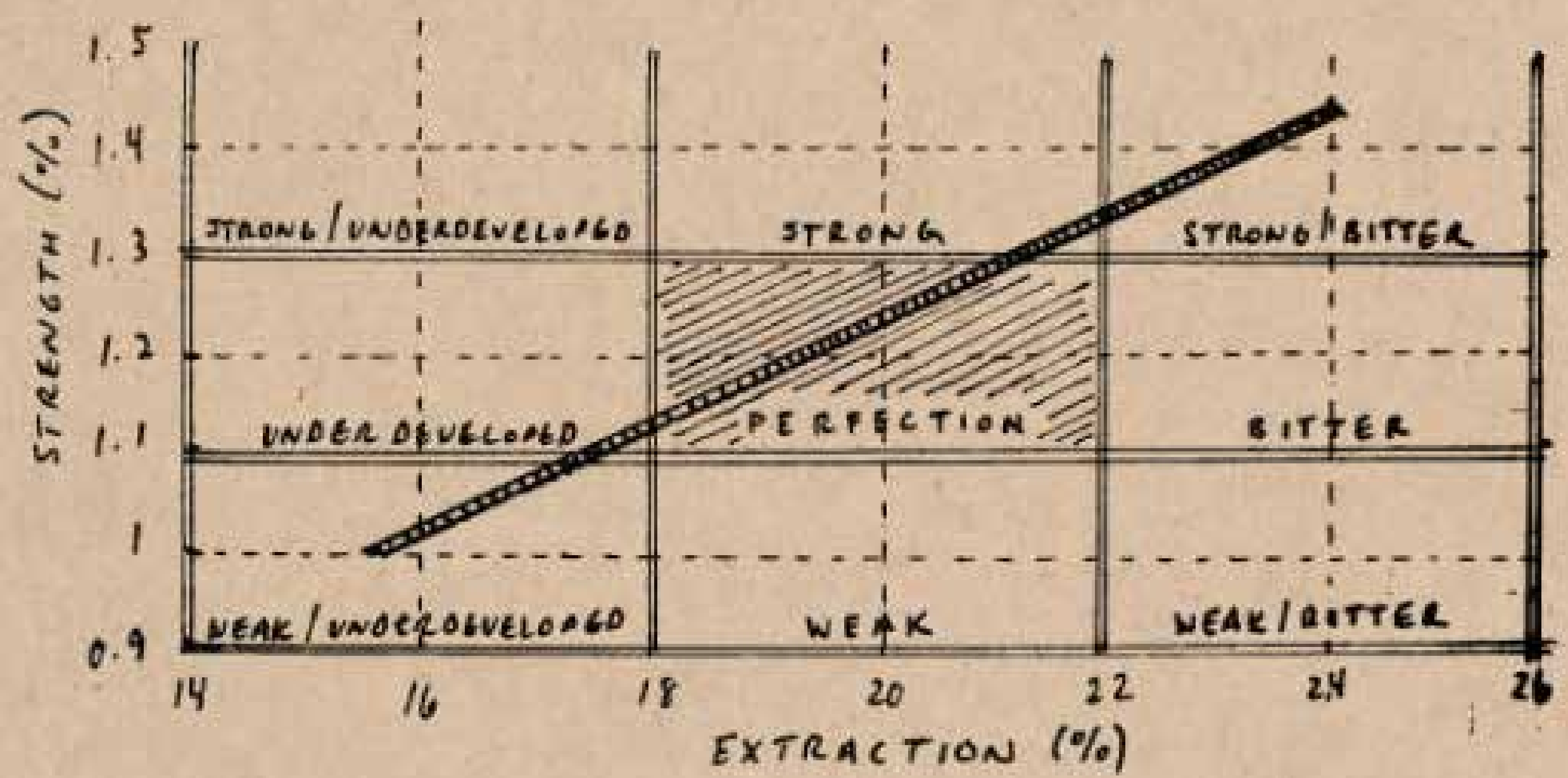

www.theatlantic.com

que se deje remojando en el agua, obteniendo así café americano agrio o amargo.

En el caso de las versiones expreso podemos describir varios aspectos importantes relativos a la tecnología, uno de ellos es el cambio del funcionamiento manual (que usan otras cafeteras) a eléctrico característico de este tipo; el tiempo de preparación que es mucho más rápido; la variedad de cafés que en ésta pueden prepararse: café expreso simple, doble, corto (más concentrado, misma cantidad de agua por el doble de café), largo (diluido con más agua) y por último la posibilidad de vaporizar leche y poder hacer otras variantes de café como cortado o marrón (con 10 a $15 \mathrm{ml}$ de leche fría), capuchino (con leche calien- te y espuma de leche, decorado con canela), latte macchiato (taza de leche entera con poco café); como resultado de la incorporación de sistemas de presión, vapor, pistón, bombas de motor o de aire, producto de la revolución industrial. En el caso de la cafetera expreso con dosis encapsuladas, el producto se ha extendido ampliamente, llegando a tener hasta 16 tipos de sabores, entre ellos: 5 tipos de intenso, 4 tipos de espresso, 4 de puro original, 3 de americano concentrado, 3 descafeinados, 3 de variaciones (caramelo, vainilla y chocolate), 1 edición limitada, esto solo para la marca Nespresso.

En las cafeteras de goteo tanto manual como automático, cuyo producto es el café americano o 

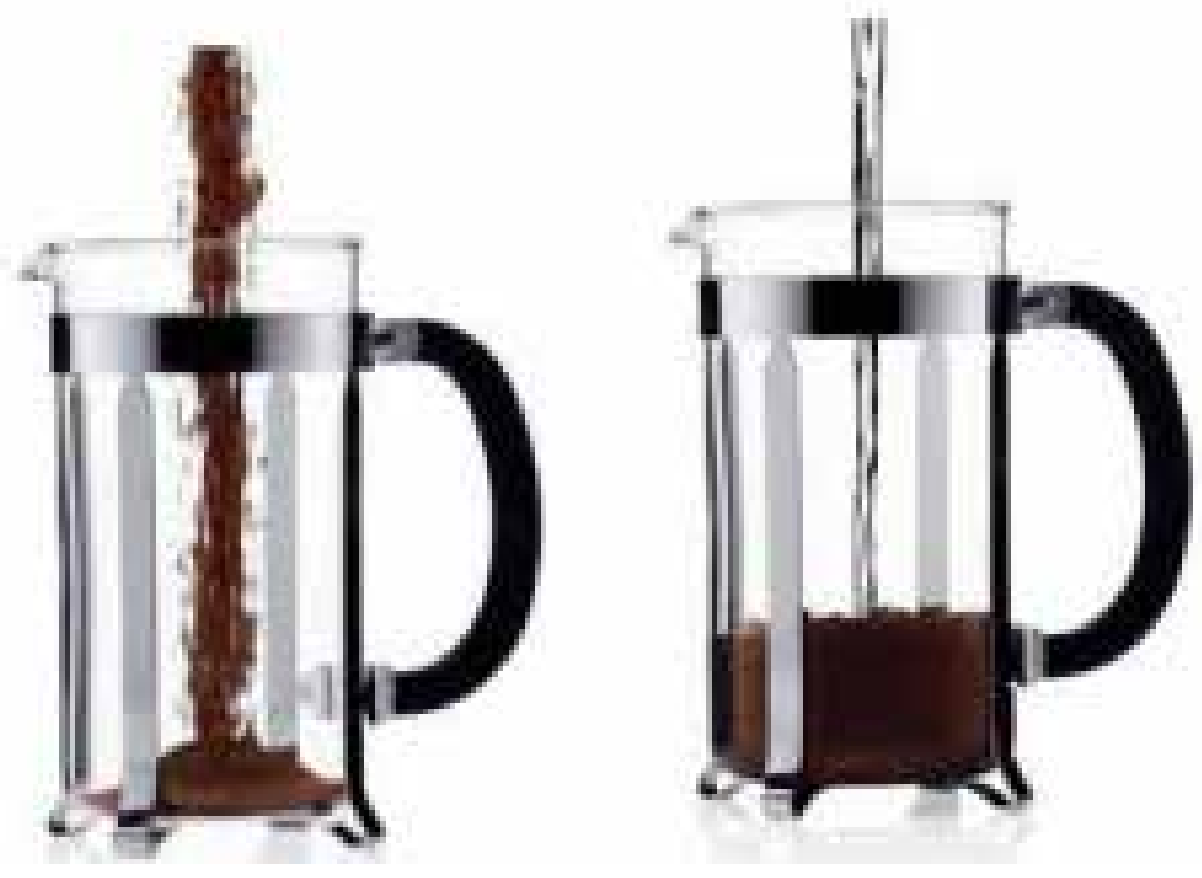

café de cuerpo ligero, la tecnología no ha afectado el funcionamiento o tipo de café, sin embargo sí ha permitido que el material usado para los filtros pueda modificarse para eliminar la mayoría de los aceites del café, mismos que hacen que la bebida sea más o menos amarga o agria.

Es importante mencionar que determinar la calidad de un café es algo muy subjetivo, porque muchas veces depende del gusto del consumidor e incluso de la parte del mundo en la que se encuentre, sin embargo en 1950 el profesor e investigador Ernest Earl Lockhart realizó diversas encuestas, mismas que documentó en una tabla denominada Coffee Brewing Control Chart, en la que de forma gráfica representó el gusto de los consumidores americanos basado en dos factores principales: la fuerza del café versus el tiempo de extracción.

\subsection{Uso}

Donald Norman en su libro El Diseño de los objetos del futuro (2010) manifiesta su preocupación en relación a que mientras la tecnología se hace más potente, su fracaso es más crítico en términos de colaboración, entendida como sincronización de actividades, la comunicación bidireccional entre artefacto-usuario y la reducción en la capacidad de entender cómo funcionan los objetos. Como resultado del proceso de análisis de las distintas cafeteras, pudimos descubrir cómo la cantidad de pasos a seguir para obtener el café ha aumentado en relación al cambio tecnológico visible en el artefacto.

En la cafetera turca los pasos para obtener el café son cinco: 1) colocar el café, 2) colocar el agua, 3) hervir, 4) dejar reposar y 5) servir; sin contar que existe la variación de preparación en donde se debe hervir y dejar reposar 4 veces para obtener un sabor más fuerte y en este caso es importante destacar que el usuario no necesita tener conocimientos previos relacionados al uso de nuevas tecnologías, siendo esta una de las más básicas y sencillas de uso. 
La cafetera de goteo automático tiene una interfaz electrónica que le permite acciones como la de prenderse a una hora específica o la de auto-apagarse después de 2 horas de uso; en esta cafetera para obtener el producto final se deben cumplir con los siguientes pasos:

\section{1) configurar el temporizador}

2) abrir el contenedor

3) colocar el filtro

4) colocar el café

5) colocar el agua

6) cerrar la tapa

7) colocar el contenedor

en el plato del calentamiento

8) encender $y$

9) servir

el doble de pasos que en la cafetera turca. En este tipo de cafeteras el usuario sí requiere de conocimientos previos en relación a las nuevas tecnologías, como saber usar un menú digital, convirtiendo a esta en una de las más complejas en su uso.

\subsection{Materiales}

El campo de desarrollo de materiales, el espectro abarca los tradicionales como la madera, el latón y el vidrio, hasta los más avanzados como el acero inoxidable de grado alimenticio, el vidrio borosilicato o el plástico $A B S$, entre otros. La revolución tecnocientífica ha influenciado los materiales a niveles antes inconcebibles, por mencionar un caso general: la cerámica antes pensada sólo para diseñar objetos domésticos o artesanales ahora puede ser utilizada como cerámica de nitruro de boro para aplicaciones cosméticas o Zirconia para productos de alto rendimiento, como relojes y cuchillos de corte, incluso en muchos casos reemplazando al acero inoxidable.

Para explicar mejor este punto haré una descripción del cambio de materiales por cada tipo de
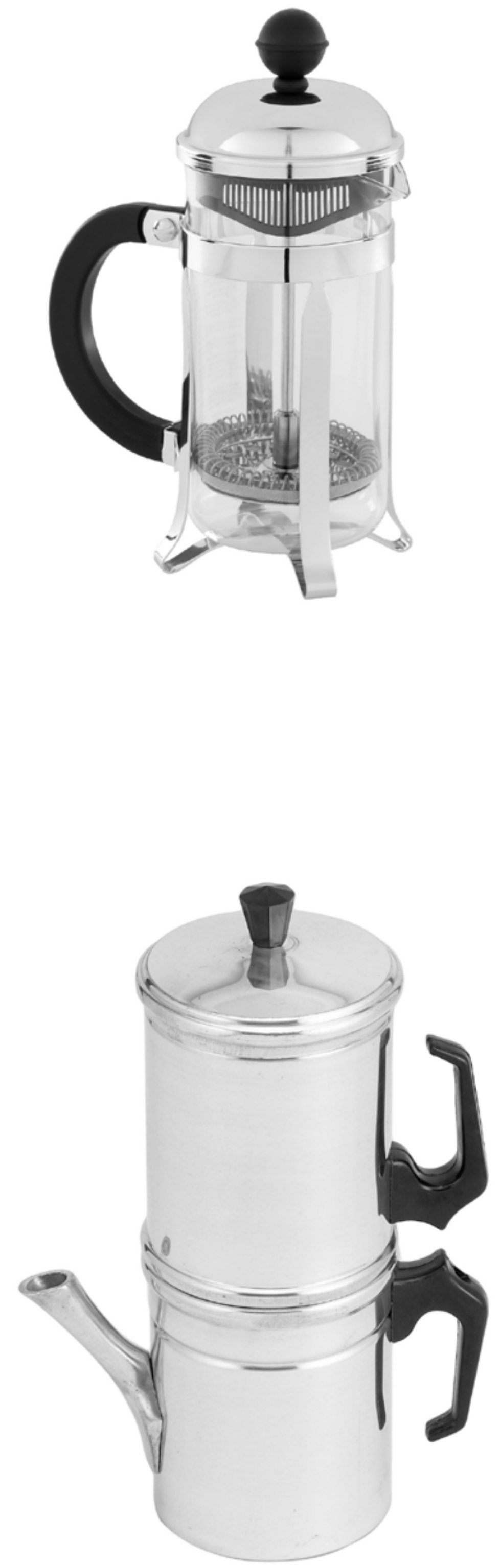


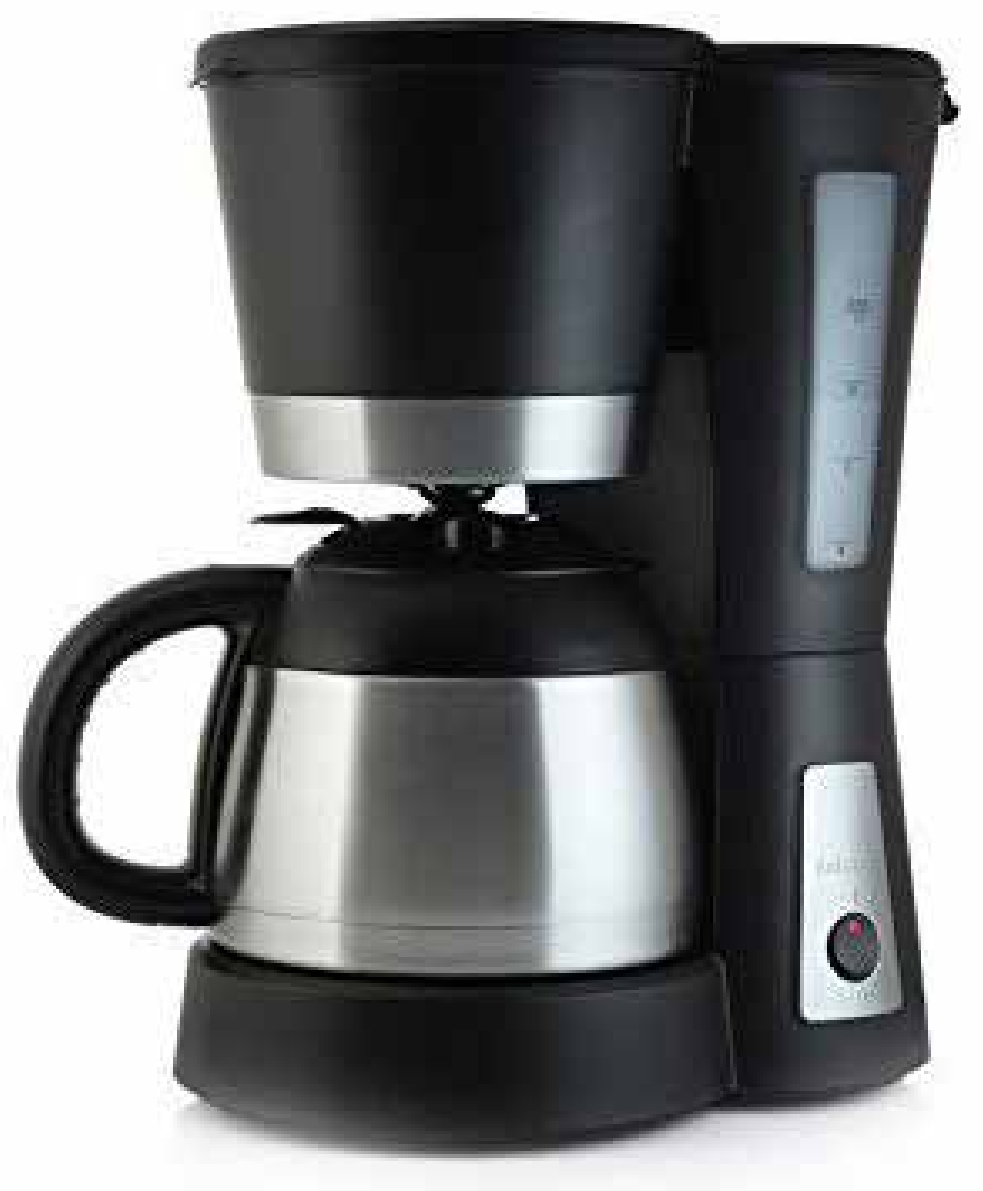

cafetera y observaremos la tecnología que cada grupo conlleva.

Cafetera turca. Inicialmente su cuerpo era realizado con cobre o latón y el asa larga de madera; en la actualidad el asa sigue siendo del mismo material, sin embargo el cuerpo se realiza con acero inoxidable.

Cafetera francesa. Los primeros diseños eran completamente metálicos, sin embargo por la falta de exactitud resultante del proceso con el que se elaboraba, el filtro no encajaba correctamente en el cuerpo y dejaba filtrar el café. En las modificaciones hechas posteriormente se agrega el sello plástico para mejorar este último inconveniente, los filtros de nylon, goma o aluminio y el cuerpo se empieza a producir en vidrio borosilicato. Hay algunas versiones en donde el mismo es de acero inoxidable para ayudar a mantener el calor por más tiempo.

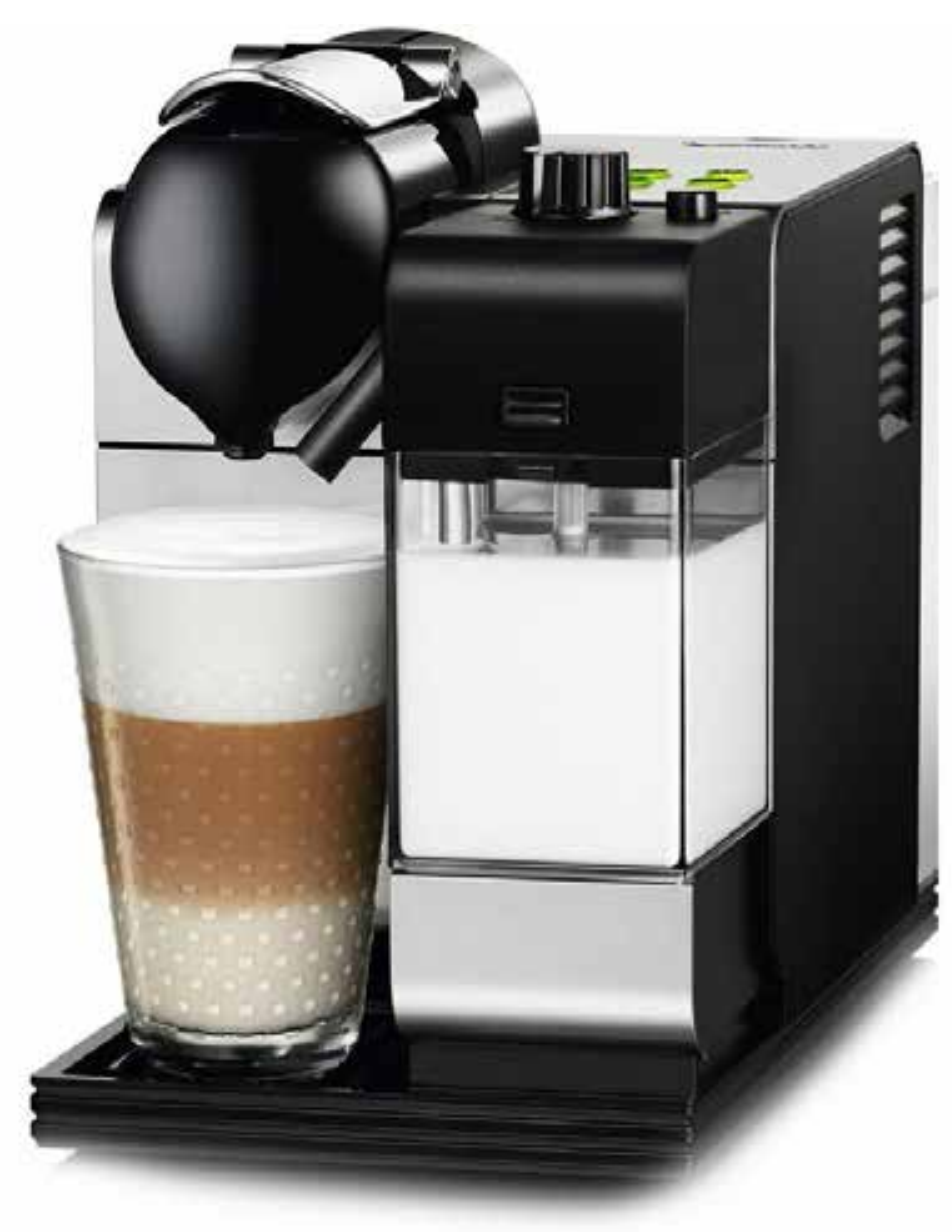

cafetera-express-nespresso

Cafetera expreso. Los modelos industriales funcionaban con un tanque metálico y el calentamiento del agua era por medio de una flama, que al hervir el agua que estaba dentro generaba el vapor; como resultado de este vapor, el agua queriendo escapar del contenedor metálico se disparaba a través de los granos del café para producir el expreso. Cuando este tipo de cafetera fue modificada por Gaggia para poder ser de uso casero, los metales utilizados cambiaron a aluminio y latón cromado; en la actualidad son elaboradas con acero inoxidable, en algunos casos metales anodizados y plástico ABS.

Cafetera de goteo manual y cafetera de goteo automático. Los cambios en materiales no han sido relevantes. En la cafetera de goteo manual su cuerpo en forma de reloj de arena es elaborado en vidrio borosilicato y la pieza de agarre en madera y cuero. Para la cafetera de goteo automático se utiliza en su mayoría plástico y acero inoxidable o metal cromado. 


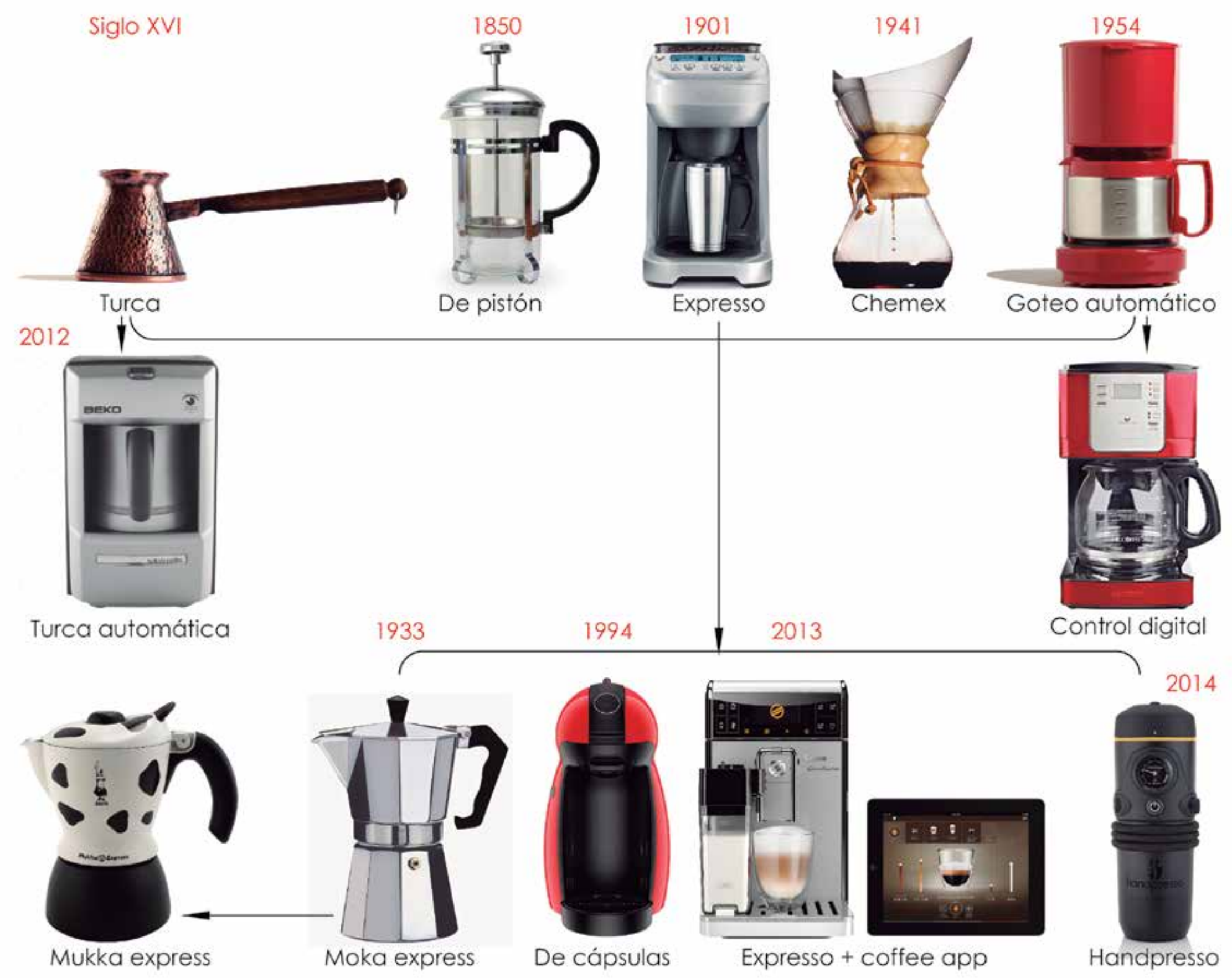

Elaboración propia

En lo que hace a la evolución de los grupos de materiales, se observó lo siguiente.

Vidrio. Antes concebido como un material frágil, de apariencia transparente y amorfa; en la actualidad ha permitido desarrollar invenciones, como la fibra óptica. Su combinación con boro nos permite tener un vidrio neutro, mejor conocido como Pyrex, con bajo coeficiente de expansión térmica, muy resistente a los choques de temperatura y ampliamente utilizado en la fabricación de utensilios de cocina y contenedores de cafeteras, como es el caso de la cafetera francesa, la de goteo manual y la de goteo automático.
Metales. Nos ofrecen versatilidad, fuerza y una apariencia estética única. Como describimos anteriormente, los primeros diseños se hacían con metales como el latón, el cual presenta desventajas, como que su capacidad de resistencia es limitada y el sobrecalentamiento puede destruir uno de sus componentes de la aleación e incluso deformarlo. Hoy en día el metal más utilizado para hacer las cafeteras o los contenedores de las mismas es el acero inoxidable de grado alimenticio. La tecnología de los procesos permite controlar las aleaciones y mezclar el acero con la cantidad exacta de cromo para evitar que haya descomposición química con las variaciones de temperatura y que pueda haber 
contacto directo con los alimentos sin afectar su sabor, textura y olor. El acero inoxidable es resistente a la corrosión, tiene excelentes propiedades higiénicas para la aplicación y es de apariencia atractiva.

Plásticos. Desde el "boom del plástico" en los años 60, la mayoría de las personas estamos familiarizadas con este material de producción masiva y bajo costo. El desarrollo tecnológico nos ha permitido ser testigos de nuevas combinaciones o aleaciones y de múltiples procesos que permiten a los diseñadores infinidad de aplicaciones, como el papel moneda hecho de plástico; los desarrollos termocromáticos que permiten al objeto cambiar de color dependiendo de la temperatura a la que esté; las espumas de alto impacto, los empaques rígidos y flexibles, entre otros. En el caso de las cafeteras, los plásticos más utilizados son el ABS (Acrilonitrilo Butadiendo Estireno) o el poliestireno de alto impacto, por su rigidez, alta resistencia al impacto y a los ataques químicos, su dureza y estabilidad al someterse a altas temperaturas; esto último como resultado de las aleaciones hechas en la II Guerra Mundial para sustituir el caucho natural.

\subsection{Procesos industriales}

En los procesos industriales de los objetos de estudio se puede observar una transformación de producción manual a producción industrial y estandarizada; incluso en el caso de las cafeteras turcas, aquellas que son elaboradas a mano se comercializan como ediciones especiales y de mayor costo. En metales, la manufactura inicialmente era realizada por procesos de martillado o fundición. Como lo vimos en la cafetera francesa, generaba problemas de ensamble correcto entre piezas. Actualmente las mismas piezas se hacen troqueladas, embutidas o con tecnología de corte CNC, que permite una precisión total entre ellas.

En los plásticos el proceso de fabricación es mol- deo por inyección, en el cual se introduce el plástico fundido a un molde cerrado con la forma de la pieza y que luego de ser enfriado permite la solidificación del material. La revolución tecnológica ha permitido que la elaboración de los moldes sea mucho más precisa y compleja, utilizando sistemas de control numérico por computadora tanto para la fabricación de éstos como para el control de las máquinas de inyección.

Para el vidrio y la madera los procesos pasaron de ser de modelado manual a soplado o torneado con maquinarias industriales que garantizan la estandarización en las piezas, la repetitividad, la producción en masa y de bajo costo.

Podemos observar cada día más cómo la tecnología ha asumido un rol importante dentro del proceso productivo en seri; la automatización de procesos permite generar piezas de alta cantidad y calidad, y cumplir de forma más óptima con el concepto de Lead manufacturing, que tiene como bases mejorar el servicio al cliente, finalizar los procesos en tiempo, reducir la sobreproducción e inventarios, disminuir costos, mejorar los tiempos de entrega, las ganancias por pieza y aumentar la calidad.

\subsection{Interfaz}

Para analizar si la tecnología ha influido en la interfaz de las cafeteras, se hizo un análisis general por medio de tablas y comparativos de características físicas, así se determinó que las únicas con presencia de esta característica eran las cafeteras expreso y las de goteo automático, que presentan el cambio más notorio. Es por ello que se hizo una comparación de ocho cafeteras eléctricas automáticas de la marca Mr. Coffee, primera en comercializar este artefacto para el hogar. Los modelos fueron seleccionados de la página web de la marca, considerando inicialmente todas aquellas que cumplieran con el requisito de ser eléctricas y 
automáticas y haciendo una agrupación por similitud en interfaz y costos. De allí fueron escogidas ocho piezas que cubrían todo el rango de precios, convirtiéndose esto en el rango de la más básica hasta la más equipada; sin importar la capacidad de tazas de café, los materiales o alguna otra característica, ya que el punto de enfoque era hacia la interfaz del usuario.

Los modelos estudiados fueron: Optimal Brew ${ }^{\mathrm{TM}}$ Thermal Coffeemaker, BVMC-LMX Series 12Cup Programmable Coffeemaker, Mr. Coffee $®$ 12-Cup Coffeemaker, TFTX Series 8-Cup Programmable Coffeemaker y DRTX Series 8-Cup Programmable Coffeemaker, BVMC-SJX Series 12-Cup Programmable Coffeemaker, JWX Series 12-Cup Programmable Coffeemaker, CGX Series 12-Cup Programmable Coffeemaker, DR Series 4-Cup Switch Coffeemaker.

En la mayoría de sus fichas técnicas, la marca expresa que las ventajas de estos modelos es que son más rápidas, que reducen el cloro del agua en un $97 \%$, que tienen un sistema de Delay Brew que permite a la cafetera empezar hasta 24 horas después de programada y varias de ellas permiten seleccionar la intensidad del café o incluyen un filtro con duración de un mes. La mitad tiene el Fresh Brew ${ }^{\mathrm{TM}}$ Timer que permite asegurar que el café esté caliente y fresco al momento de tomarse y tienen un sistema de autolimpieza. Todas tienen Pause N' Serve, que permite que el usuario se sirva una taza durante el proceso de elaboración y que la cafetera se auto apague a las 2 horas.

En relación a la interfaz del usuario, el modelo más básico, la DR Series 4-Cup Switch Coffeemaker, tiene sólo un botón de ON/OFF con una luz indicador verde que se activa cuando se encuentra encendida; cabe destacar que ésta es una de las más económicas.

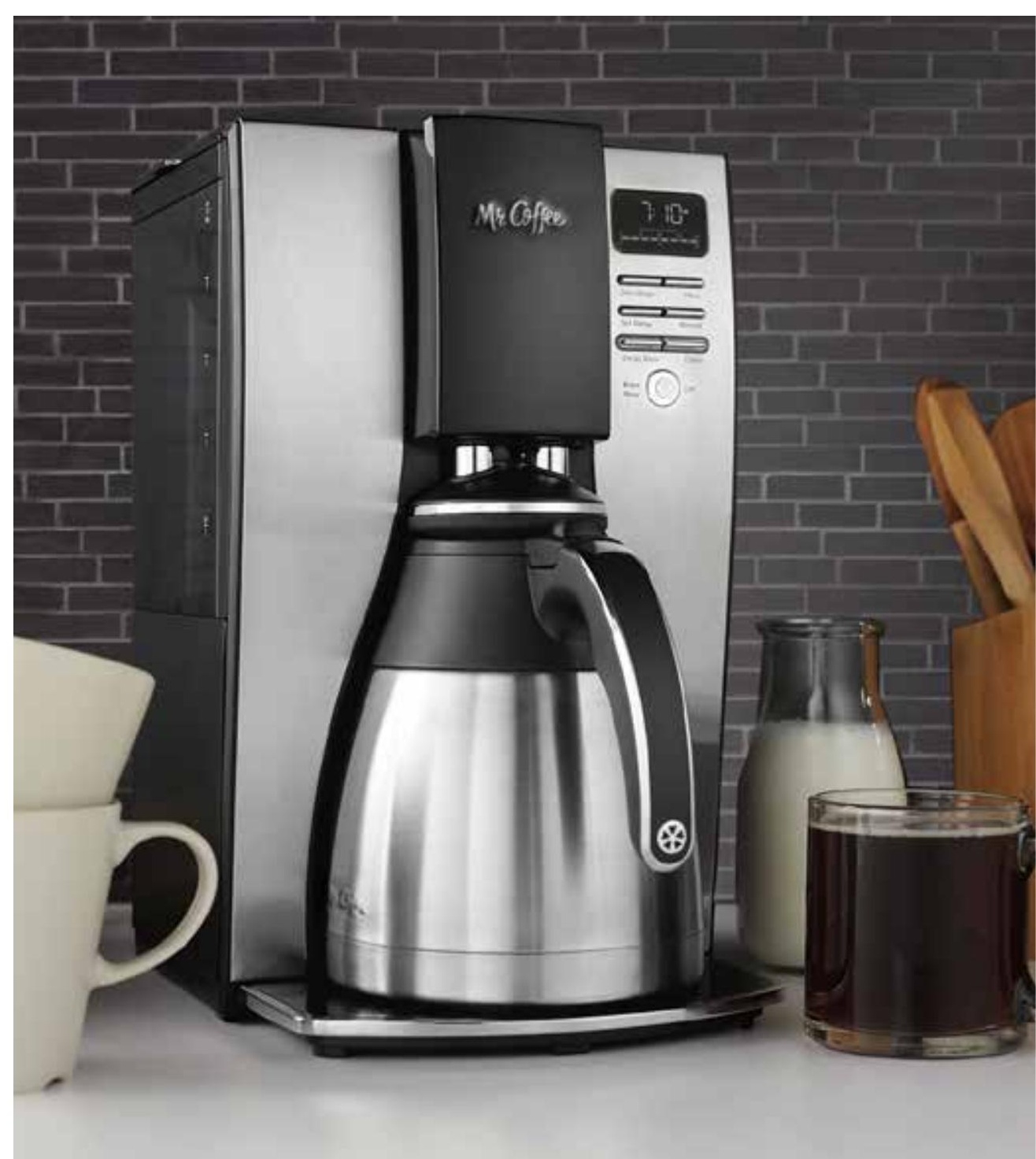

Optimal Brew ${ }^{\mathrm{TM}}$ Thermal Coffee Maker | www.mrcoffee.com

Los modelos intermedios en costo tienen una pantalla digital que indica la hora, con diferentes botones de configuración de la misma y en algunos casos el botón de set delay y fresh brew timer. Para los botones de encendido, dos de cinco modelos tienen el botón de ON/OFF con una luz roja o verde para indicar cuando está encendida, y la otras tres tienen una serie de botones que se presentan de la siguiente manera:

Modelo Mr. Coffee® 12-Cup Coffeemaker y JWX Series 12-Cup Programmable Coffeemaker: botones de Select/OFF con indicadores de luz rojo (clean), amarillo (delay brew), verde (brew now) y brew strenght -intensidad del café, rojo (strong) y verde (regular). 


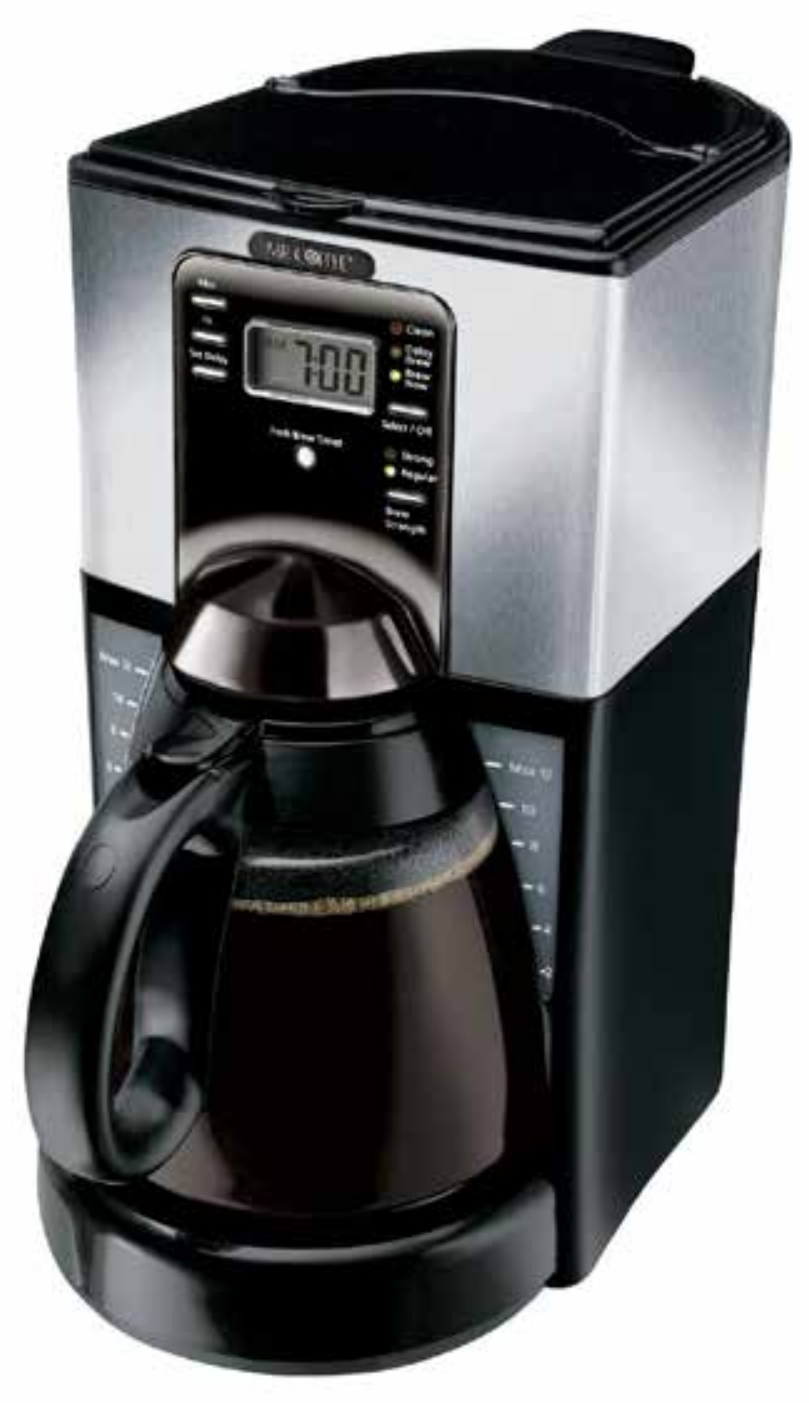

BVMC-LMX Series 12-Cup Programmable Coffeemaker

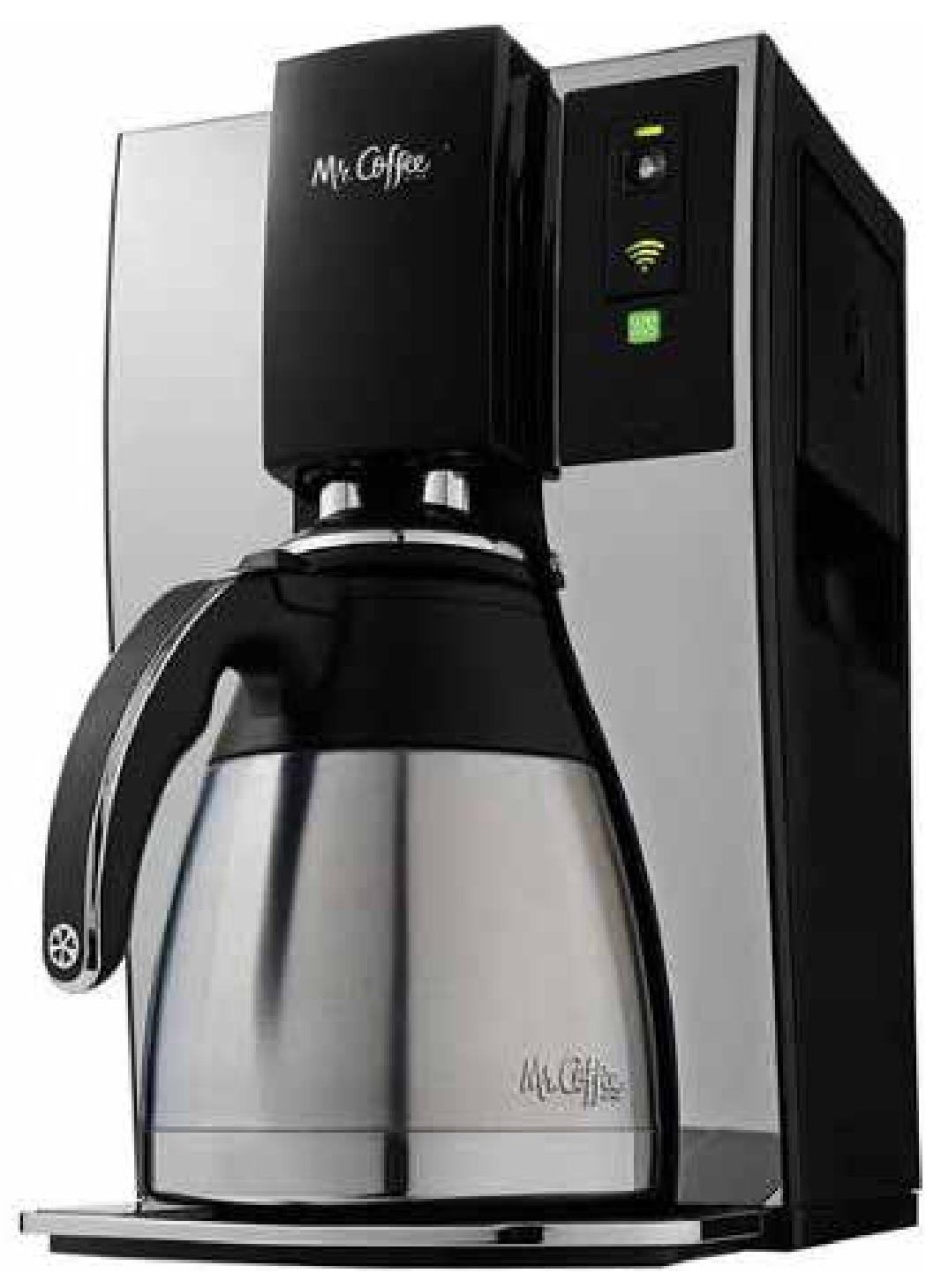

Optimal Brew ${ }^{\mathrm{TM}}$ Thermal Coffeemaker
El BVMC-SJX Series 12-Cup Programmable Coffeemaker aparte de presentar los botones anteriores también incluye indicadores de luz azul para glass o thermal -opción referida al material del contenedor de café si es de vidrio o térmico- y el ícono de la carafe o contenedor.

En cuanto a los dos modelos más caros de los seleccionados, la BVMC-LMX Series 12-Cup Programmable Coffeemaker tiene una pantalla de reloj y tiempo de preparación digital con apariencia analógica y botones de fresh brew timer, configuración strong o regular coffee, delay brew, clean, set delay, configuración de la hora (hora y minutos), preparación Now/OFF; y la Optimal Brew ${ }^{\mathrm{TM}}$ Thermal Coffeemaker tiene una pantalla de reloj y tiempo de preparación digital, así como botones de Sleep Mode, configuración de hora (hora y minutos), set delay, preparación ON/OFF.

Retomando los otros modelos estudiados, cabe destacar una variación de la cafetera Phillips GranVaristo Avanti, la cual crea diferentes bebidas de café a través de un smart device, móvil o tablet; tiene una aplicación social para compartir recetas, tipos de granos, y la pantalla de la cafetera es touch. 


\section{Conclusiones}

Retomando el objetivo de estudio que pretende describir la relación entre la transformación de las cafeteras y el desarrollo tecnológico, pudimos determinar que en la mayoría de los casos sí ha habido una influencia directa de la revolución tecnocientífica en la forma, la función, el uso, los materiales, los procesos utilizados y en la interfaz.

En el caso de la función, se pudo especificar que en un inicio sólo se podía producir café agrio o amargo y en la actualidad podemos obtener múltiples tipos de café en una sola cafetera. También se identifica un incremento en los pasos a seguir para obtener el producto final como resultado de esta incorporación de funciones más complejas, que van más allá de tan solo hacer café. Para los materiales y procesos se determinó una influencia directa de la tecnología en términos de generar aleaciones y materiales más resistentes, poder procesarlos y convertirlos en objeto de forma más compleja y versátil, y tener líneas de producción automatizadas que aumentan la calidad de las piezas y aminoran los costos de las mismas. $Y$ por último, la interfaz se ha ido transformando de pantallas análogas o botones de encendido a pantallas digitales con diferentes menús y actividades programables, llegando hasta el ejemplo de configurarla por medio de aplicaciones en móviles y tabletas, que incluso acotan la interacción directa del usuario con la cafetera.

En el campo del diseño industrial quedan asignaturas pendientes, por ejemplo la relación entre la complejidad de funciones, el uso y la interfaz con el diseño universal o inclusivo, y si estos objetos pueden ser utilizados por personas de cualquier edad, habilidad o situación económica. También si la revolución tecnológica ha influenciado la apariencia o estética del producto, al punto de modificar la composición formal y el lenguaje de las cafeteras.

Citando a Alice Rawsthorn, editora de diseño del International Herald Tribune en la película Objectified (2009): "Ahora tenemos una nueva generación de productos en los que la forma tiene absolutamente ninguna relación con la función. Mira algo como el iPhone y piensa en todas las cosas que hace. "La forma sigue a la función", ha sido aniquilado por el microchip.", sería interesante comprobar si esta declaración aplica también para las cafeteras.

\section{Referencias}

- Ashby M. \& Johnson K., (2002). Materials and Design: The Art and Science of Material Selection in Product Design. Oxford: Elsevier Butterworth-Heinemann. - Castells M., (1996). La era de la información. México: Siglo Veintiuno. • Castells M., (1996). 'La sociedad red'. In: (ed), La era de la información. México: Siglo Veintiuno. p.35. • Durán O., (2011). El Diseño Industrial y el Cambio Tecnológico. Revista Colombiana de Filosofía de la Ciencia. XI (22), pp.97-114.• Durán O., (2011). El Diseño Industrial y el Cambio Tecnológico. Revista Colombiana de Filosofía de la Ciencia. XI (22), pp.110. - Echeverría J, (2003). La Revolución tecnocientífica. 1st ed. España: Fondo de Cultura Económica de España. - Estudillo García J., (2001). Surgimiento de la sociedad de la información. Biblioteca Universitaria Nueva Época. 4, pp.77-86 - Mateo Hernández J. (2013). Una definición del Diseño Industrial. [ONLINE] Recuperado de: http://www. xn-diseadorindustrial-q0b.es/index.php?/queeseldiseno/05-definicion-de-diseno-industrial/. • Norman D., (2010). El diseño de los objetos del futuro. La interacción entre el hombre y la máquina. España: Paidós Ibérica. • Watts Duncan, (2006). Seis grados de separación: la ciencia de las redes en la era del acceso. Barcelona, España: Paidós Ibérica. - Xue, L., Yen, C.C., Boucharenc, C. and Choolani, M. (2008) "The design evolution of medical devices: moving from object to user", J. Design Research, Vol. 7, No. 4, pp.411-438. 